\title{
Unresectable Intrahepatic Cholangiocarcinoma
}

National Cancer Institute

\section{Source}

National Cancer Institute. Unresectable Intrahepatic Cholangiocarcinoma. NCI

Thesaurus. Code C148432.

Intrahepatic cholangiocarcinoma that is not amenable to surgical removal. 